\title{
Identification of Candida species in formalin fixed, paraffin wax embedded oral mucosa by sequencing of ribosomal DNA
}

\author{
D W Williams, M J Wilson, M A O Lewis, A J C Potts
}

\begin{abstract}
Aim-To identify Candida species in formalin fixed, paraffin wax embedded tissue by sequencing candidal rDNA.

Methods-Target rDNA sequences were amplified by polymerase chain reaction (PCR) from fresh isolates of Candida and from 18 preserved oral mucosal tissue samples (16 cases of chronic hyperplastic candidiasis and two fibroepithelial polyps), shown histologically to contain Candida. Identification of Candida species within tissue was based on a comparison of the rDNA sequences obtained with those from the fresh isolates of Candida and those present in the GenBank database.

Results-The PCR products obtained from 12 of the 18 tissue specimens studied were characteristic of Candida albicans. In two of these cases a second, larger PCR product was obtained and these sequences were characteristic of Candida glabrata. Conclusions-Candidal DNA was amplified successfully from formalin fixed, paraffin wax embedded tissue. Sequencing of the PCR product enabled identification of the Candida species present.

(f Clin Pathol: Mol Pathol 1996;49:M23-M28)
\end{abstract}

Keywords: Candida, PCR, rDNA, formalin fixed paraffin wax embedded sections.

The use of modern chemotherapeutic regimens such as immunosuppressive and corticosteroid therapies has been associated with an increase in the incidence of opportunistic infections involving Candida. ${ }^{12}$ Although deep seated candidal infection in immunocompromised individuals can arise, ${ }^{3}$ superficial infections of the oral and vaginal mucosa are the most frequently occurring forms of candidiasis. ${ }^{2}$ Confirmation of these infections is made by culture and identification of Candida isolates. Candida albicans is regarded as the most pathogenic species but other species, such as $C$ tropicalis, $C$ parapsilosis, $C$ glabrata, $C$ guilliermondii, and $C$ krusei, have also been implicated in human disease. $^{4}$

Chronic hyperplastic candidiasis (CHC), a form of candidiasis which affects the oral mucosa, has received particular attention as it has been associated with the development of intraoral malignancy. ${ }^{5}$ The isolation of Candida from the mucosal surface is not sufficient for a diagnosis of $\mathrm{CHC}$ because Candida are often re- covered in low numbers and differentiation from the level accepted as normal commensal carriage is difficult. ${ }^{6}$ Diagnosis of $\mathrm{CHC}$, therefore, is based on microscopic examination of lesional tissue for the presence of structures consistent with fungal hyphae. Unfortunately, techniques confirming these structures to be candidal hyphae would not seem to have been reported.

Human soft tissue biopsy material is routinely preserved by fixation in formalin and subsequent embedding in paraffin wax. The advent of versatile gene amplification technologies, including the polymerase chain reaction (PCR), ${ }^{7}$ has enabled the rapid and sensitive amplification of DNA from such archival material. Human gene abnormalities, viral DNA and bacterial DNA have been detected in formalin fixed, paraffin wax embedded tissue using PCR and other molecular techniques. ${ }^{8-11}$ However, procedures based on molecular biology have not been reported for the detection of fungi in archival tissue.

Candidal rDNA sequences have been used as a basis for the identification of clinical isolates of medically important Candida species either by sequencing or restriction fragment length polymorphism analysis. ${ }^{12-14}$ The rDNA sequences of Candida provide suitable targets for PCR as they comprise both conserved and variable regions. Conserved regions are ideal targets for the design of PCR primers whilst the intervening variable regions are often species or strain specific.

The aim of the present study was to develop an approach based on sequence analysis of candidal rDNA regions that would permit identification of Candida within formalin fixed, paraffin wax embedded samples of oral mucosa.

\section{Methods}

Pure cultures of 11 Candida isolates, shown in table 1 , were initially examined to establish a reference base of product size and sequence. The identity of all isolates was confirmed by germ tube formation and use of the API-20C carbohydrate assimilation system (bioMérieux; Basingstoke, UK). Isolates were cultured for 24 hours in yeast nitrogen base medium (Difco, East Moseley, UK) at $37^{\circ} \mathrm{C}$, and the DNA extracted as described previously. ${ }^{14}$ Five microlitres (approximately $100 \mu \mathrm{g} / \mathrm{ml} \mathrm{DNA}$ ) of the extract was added to $45 \mu \mathrm{l}$ water and used as template for PCR. 
Table 1 PCR product sizes obtained by amplification of $r D N A$ regions from 11 Candida isolates using three primer pairs

\begin{tabular}{llll}
\hline & \multicolumn{3}{l}{ Primer pair and PCR product size (bp) } \\
\cline { 2 - 4 } Candida isolate & Pcon1 and & ITS1 and & ITS1 and \\
\hline C albicans 121 & $105^{*}$ & 218 & $535^{*}$ \\
C albicans 324 & 105 & 218 & $535^{*}$ \\
C albicans 655 & $105^{*}$ & 218 & $535^{*}(\mathrm{~L} 47111)$ \\
C tropicalis 340 & $105^{*}$ & 218 & $524^{*}(\mathrm{~L} 47112)$ \\
C tropicalis 722 & 105 & 218 & $524^{*}$ \\
C stellatoidea NCPF 3108 & 105 & 219 & $540^{*}(\mathrm{~L} 47114)$ \\
C parapsilosis 937A & $105^{*}$ & 229 & $520^{*}(\mathrm{~L} 47109)$ \\
C krusei 3165 & $105^{*}$ & 183 & $510^{*}(\mathrm{~L} 47113)$ \\
C guilliermondii 657b & $105^{*}$ & $249^{*}$ & $608^{*}(\mathrm{~L} 47110)$ \\
C kefyr (pseudotropicalis) Y06.07 & $105^{*}$ & 309 & $720^{*}(\mathrm{~L} 47107)$ \\
C (Torulopsis) glabrata 955 & $105^{*}$ & $478^{*}$ (L47108) & 878 \\
\hline
\end{tabular}

$\mathrm{bp}=$ base pairs; *products sequenced; GenBank accession number given in brackets.

The archival tissue material had originally been fixed in at least a 10 -fold volume of $10 \%$ buffered formal saline for 24 hours prior to processing through graded alcohol and xylene and embedding in paraffin wax. Eighteen blocks of tissue shown to contain structures consistent with candidal hyphae on staining with periodic acid-Schiff (PAS) were selected for further study.

Positive control material was prepared by resuspending $C$ albicans (strain 655 ) in $0.4 \%$ molten agarose which, after solidifying, was preserved in the same manner as test tissues.

Sections $(2 \times 20 \mu \mathrm{m})$ of archival and positive control material were placed in $1.5 \mathrm{ml}$ microtubes and deparaffinised by the addition of xylene $(1 \mathrm{ml})$ for 10 minutes. After centrifugation (12500 rpm for 10 minutes), the pelleted material was washed once in ethanol and dried. The dried material was resuspended in $200 \mu \mathrm{l}$ proteinase $\mathrm{K}$ buffer $(1 \mathrm{mg} / \mathrm{ml}$ proteinase K (Sigma, Poole, Dorset, UK), $50 \mathrm{mM}$ Tris $/ \mathrm{HCl}$ (pH 8.5), $1 \mathrm{mM}$ EDTA, and $0.5 \%$ Tween 20) and incubated at $37^{\circ} \mathrm{C}$ for six days. The solution was then heated to $95^{\circ} \mathrm{C}$ for 30 minutes to inactivate proteinase $\mathrm{K}$, and $50 \mu \mathrm{l}$ of the cooled solution used as template for PCR.

Four pairs of PCR primers were used (table 2). The PCR conditions for each set of primers have been described previously. ${ }^{11416}$ Negative controls using sterile water in place of DNA were included alongside each amplification reaction.

The presence and size of PCR products were assessed by agarose gel electrophoresis and ethidium bromide staining. ${ }^{17}$ Purification of the PCR products from the tissues and cultures of Candida was achieved using the QIAquick Spin PCR Purification Kit (Qiagen, Dorking, UK). In cases where two distinct PCR products of differing sizes resulted from the same tissue, isolation and purification of each product from the agarose gel was performed using a similar, commercially available system (QIAquick Gel Extraction Kit; Qiagen).

Sequencing of both strands of the purified candidal PCR products $(0.5 \mu \mathrm{g})$ was performed using the original PCR primers and the Prism Ready Reaction DyeDeoxy Terminator Cycle Sequencing Kit (Perkin Elmer), in accordance with the manufacturer's instructions. The resulting dideoxy products were analysed using an Applied Biosystems 373A automated sequencer. The sequences obtained and those retrieved from GenBank and EMBL databases (SERC, Daresbury Laboratory, Warrington, UK) were aligned using the CLUSTAL $v$ suite of programs, and distance values calculated with the DNA DIST software program (University of Wisconsin Genetics Computer Group). ${ }^{18}$

\section{Results}

PCR AMPLIFICATION

Table 1 illustrates the product size (determined by gel electrophoresis and sequencing) following PCR amplification of DNA extracted from 11 pure cultures of $C$ andida. PCR products of the same size (105 base pairs) were obtained with all isolates tested with primers Pcon 1 and Pcon2. Using the ITS1 and ITS2 primer pair, isolates identified as $C$ krusei, $C$ guilliermondii, $C$ kefyr (pseudotropicalis), and $C$ (Torulopsis) glabrata yielded products of 183, 249, 309, and 478 base pairs, respectively. In the case of the remaining strains, similarly sized products (220-230 base pairs) were obtained (fig 1A). Using primers ITS 1 and ITS4, isolates identified as $C$ guilliermondii, $C$ kefyr ( $p$ seudotropicalis) and $C$ (Torulopsis) glabrata yielded product sizes of 608,720 and 878 base pairs, respectively. Products of 510-540 base pairs were obtained from the remaining strains (fig $1 \mathrm{~B}$ ).

PCR AMPLIFICATION OF DNA IN FORMALIN FIXED, PARAFFIN WAX EMBEDDED MATERIAL Table 3 shows the results of PCR performed on DNA extracted from formalin fixed, paraffin wax embedded material with the different primer pairs. Amplification of human $\beta$-actin gene sequences (202 base pairs) with primers AW75 and AW76 occurred in 15 of the 18 tissue samples tested. Products of the expected size were also observed with $C$ albicans embedded in the positive control agarose material using each of the three primer pairs directed

Table 2 Primers used to amplify DNA extracted from Candida isolates and archival tissue

\begin{tabular}{|c|c|c|c|c|}
\hline Primer & Primer sequence $\left(5^{\prime}-3^{\prime}\right)$ & Target DNA & Expected product size (bp) & Reference \\
\hline $\begin{array}{l}\text { AW75 } \\
\text { AW76 }\end{array}$ & $\begin{array}{l}\text { CCTTCCTGGGCATGGAGTCCTG } \\
\text { GGAGCAATGATCTTGATCTTC }\end{array}$ & Human $\beta$-actin DNA & 202 & Ghossein et $a l^{\prime \prime}$ \\
\hline $\begin{array}{l}\text { ITS1 } \\
\text { ITS4 }\end{array}$ & $\begin{array}{l}\text { TCCGTAGGTGAACCTGCGG } \\
\text { TCCTCCGCTTATTGATATGC }\end{array}$ & $\begin{array}{l}\text { ITS1, } 5.8 S \text { and ITS2 } \\
\text { rDNA regions }\end{array}$ & 535 (C albicans) & White $e t a l^{15}$ \\
\hline $\begin{array}{l}\text { ITS1 } \\
\text { ITS2 }\end{array}$ & $\begin{array}{l}\text { TCCGTAGGTGAACCTGCGG } \\
\text { GCTGCGTTCTTCATCGATGC }\end{array}$ & ITS1 rDNA region & 218 (C albicans) & White et $a l^{15}$ \\
\hline $\begin{array}{l}\text { Pcon1 } \\
\text { Pcon2 }\end{array}$ & $\begin{array}{l}\text { AGTTTCGCGTATGGTCTCCC } \\
\text { GTTGCGGCCATATCTAGCAG }\end{array}$ & Candidal 5S rDNA & 105 (C albicans) & Holmes et $a l^{16}$ \\
\hline
\end{tabular}


A

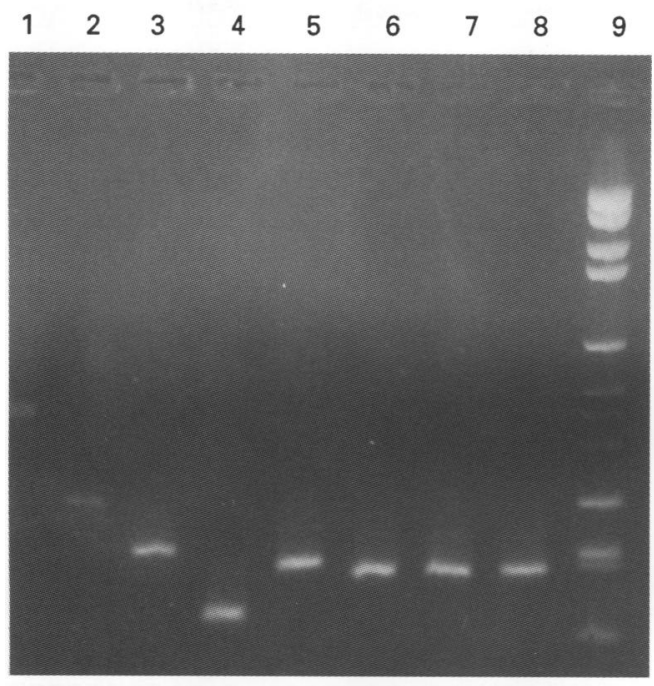

B

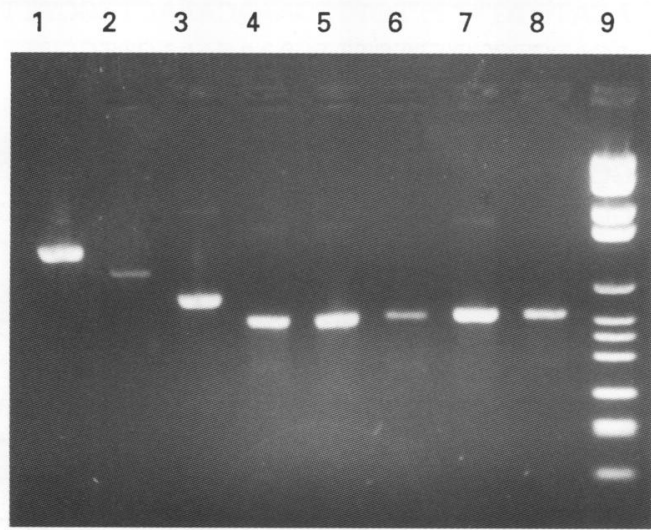

Figure 1 (A) PCR amplification of candidal $r D N A$ with primers ITS1 and ITS2. (B) PCR amplification of candidal rDNA with primers ITS1 and ITS4. Lanes 1 to 8 contain DNA from $\mathrm{C}$ glabrata, $\mathrm{C}$ guilliermondii, $\mathrm{C}$ kefyr, C krusei, C parapsilosis, C stellatoidea, $C$ tropicalis, and $\mathrm{C}$ albicans, respectively. Lane 9 contains a molecular weight marker.

against candidal rDNA. Twelve of the 18 tissue samples yielded PCR products of about 105 base pairs with the Pcon1/Pcon 2 primer pair. Products of 218 base pairs were also obtained

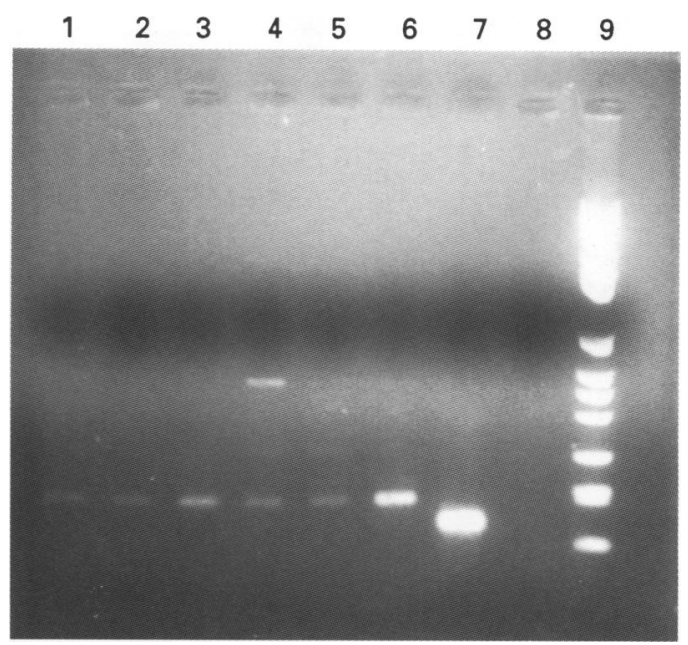

Figure $2 P C R$ amplification of candidal $r D N A$ extracted from formalin fixed, paraffin wax embedded tissue with primers ITS1 and ITS2. Lanes 1 to 6 contain DNA from the following formalin fixed tissue samples: D92.1639, D92.865, D95.227, D92.791, D95.126, and D88.169. Lanes 7 and 8 contain DNA from C krusei and a water control, respectively. Lane 9 contains a molecular weight marker.

from these samples using the ITS1/ITS2 primer pair (fig 2). In two of these 12 tissue samples a second, larger PCR product (478 base pairs) was also observed. Using primers ITS1 and ITS4, 535 base pair PCR products were generated from two of the 18 samples tested.

DIRECT SEQUENCING OF PCR PRODUCTS

The Pcon $1 /$ Pcon 2 PCR product from five tissue samples and eight Candida cultures was sequenced (tables 1 and 3 ). When Pcon1/ Pcon 2 product sequences generated from pure cultures of Candida and database sequences ( $C$ parapsilosis, EMBL accession no. D10535 and $C$ albicans, EMBL accession no. X16634) were compared, it was apparent that there was insufficient variation to enable speciation.

Sequencing of PCR products obtained from pure cultures of Candida (table 1) with the ITS1 and ITS 2 primers showed that each Candida species yielded an identifiable product se-

Table 3 PCR product sizes obtained by amplification of DNA from formalin fixed, paraffin wax embedded tissues using four different primer pairs

\begin{tabular}{|c|c|c|c|c|c|}
\hline \multirow[b]{2}{*}{ Tissue reference } & \multirow[b]{2}{*}{ Origin of tissue $\dagger$} & \multicolumn{4}{|c|}{ Primer pair and product size (bp) } \\
\hline & & $A W 75$ and $A W 76$ & Pcon 1 and Pcon 2 & ITS1 and ITS2 & ITS1 and ITS4 \\
\hline Positive control & & & 105 & 218 & 535 \\
\hline D88.169 & $\mathrm{CHC}$ & 202 & $105^{*}$ & $218^{*}$ & No product \\
\hline D88.389 & CHC & No product & No product & No product & No product \\
\hline D88.404 & $\mathrm{CHC}$ & No product & No product & No product & No product \\
\hline D89.912 & $\mathrm{CHC}$ & 202 & 105 & 218 and 479 & No product \\
\hline D90.665 & $\mathrm{CHC}$ & 202 & 105 & 218 & No product \\
\hline D91.697 & $\mathrm{CHC}$ & 202 & No product & No product & No product \\
\hline D91.98 & $\mathrm{CHC}$ & 202 & 105 & $218^{*}$ & No product \\
\hline D92.641 & $\mathrm{CHC}$ & 202 & No product & No product & No product \\
\hline D92.791 & $\mathrm{CHC}$ & 202 & $105^{*}$ & 218 and $479^{*}$ & No product \\
\hline D92.865 & $\mathrm{CHC}$ & 202 & $105^{*}$ & $218^{*}$ & No product \\
\hline D92.1000 & $\mathrm{CHC}$ & No product & No product & No product & No product \\
\hline D92.1639 & $\mathrm{CHC}$ & 202 & $105^{*}$ & $218^{*}$ & No product \\
\hline D93.1497 & $\mathrm{CHC}$ & 202 & 105 & $218^{*}$ & No product \\
\hline D93.1498 & $\mathrm{CHC}$ & 202 & $105 *$ & 218 & 535 \\
\hline D93.1521 & $\mathrm{CHC}$ & 202 & $105^{*}$ & 218 & 535 \\
\hline D95.126 & Fibroepithelial polyp & 202 & 105 & 218 & No product \\
\hline D95.227 & Fibroepithelial polyp & 202 & 105 & $218^{*}$ & No product \\
\hline D95.400 & $\mathrm{CHC}$ & 202 & No product & No product & No product \\
\hline
\end{tabular}

† Tissues previously shown to contain structures consistent with Candida hyphae by microscopic examination; $\mathrm{CHC}=\mathrm{chronic}$ hyperplastic candidiasis; * products sequenced. 
$C$ albicans $\times 71088^{\dagger}$

$C$ albicans 655

$C$ tropicalis 340

$C$ krusei 3165

D88.169

D91. 98

D92.865

D92.1639

D93.1497

D95. 227

$C$ albicans $\times 71088^{\dagger}$

$C$ albicans 655

$C$ tropicalis 340

$C$ krusei 3165

D88.169

D91. 98

D92. 865

D92. 1639

D93.1497

D95.227

$C$ albicans $\times 71088^{\dagger}$

$C$ albicans 655

$C$ tropicalis 340

C krusei 3165

D88.169

D91. 98

D92. 865

D92.1639

D93.1497

D95. 227

$C$ albicans $\times 71088^{\dagger}$

$C$ albicans 655

$C$ tropical 340

C krusei 3165

D88.169

D91. 98

D92.865

D92.1639

D93.1497

D95. 227

$C$ albicans $\times 71088^{\dagger}$

$C$ albicans 655

$C$ tropicalis 340

$C$ krusei 3165

D88.169

D91. 98

D92.865

D92.1639

D93.1497

D95.227
TCCGTAGGTGAACCTGCGGAAGGATCATTACTGATTTGCTTAATTGCACC TCCGTAGGTGAACCTGCGGAAGGATCATTACTGATTTGGTGAATTGCACC TCCGTAGGTGAACCTGCGGAAGGATCATTACTGATTTGCTTAATTGCACC TCCGTAGGTGAACCTGCGGAAGGATCATTACTG--TGATTTA---GTACT TCCGTAGGTGAACCTGCGGAAGGATCATTACTGATTTGCTTAATTGCACC TCCGTAGGTGAACCTGCGGAAGGATCATTXCTGATTTGCXTAATTGCACC TCCGTAGGTGAACCTGCGGAAGGATCATTACTGATTTGCTTAATTGCACC TCCGTAGGTGAACCTGCGGAAGGATCATTACTGATTTGCTTAATTGCACC TCCGTAGGTGAACCTGCGGAAGGATCATTACTGATTTGCTTAATTGCACC TCCGTAGGTGAACCTGCGGAAGGATCATTACTGATTTGCTTAATTGCACC

ACATGTGTTTTTCTTTGAAACAAACTTGCTTTGGCGGTGGGCC-CAGCCT ACATGTGTTTTTCTTTGAAACAAACTTGCTTTGGCGGTGGGCC-CAGCCT ACATGTGTTTTTTATTG-AACAAATTT-CTTTGGTGGCGGGAGCAATCCT ACAC-TGCGTGAGC--GGAACGAAX-..... - ACAACAA - -.- CACCT ACATGTGTTTTGTTTTGGA-CAAACTTGCTTTGGCGGTGGGCCTCTACCT ACATGTGTTTTGTTTTGGA-CCAACTTGCTTTGGCGGTGGGCCTCTACCT ACATGTGTTTTGTTTTGGA-CAAACTTGCTTTGGCGGTGGGCCTCTACCT ACATGTGTTTTGTTTTGGA-CAAACTTGCTTTGGCGGTGGGCCTCTACCT ACATGTGTTTTTCTTTGAAACAAACTTGCTTTGGCGGTGGGCC-CAGCCT ACATGTGTTTTTCTTTGAAACAAACTTGCTTTGGCGGTGGGCC-CAGCCT

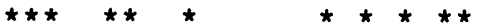

$\star \star \star$

GCCGCCAGAGGTC-TAAACTTACAACCA-ATTTTTTATCAACTTGTCACA GCCGCCAGAGGTC-TAAACTTACAACCA-ATTTTTTATCAACTTGTCACA ACCGCCAGAGGTTATAA - CTA-AACCAAACTTTTTATTTACA-GTCAAA -...- - AAAATGTGGAAT-ATAGC -...-. - ATATAGTCGACAAG GCCGCCAGAGGACATAAACTTACAACCAAATTTTTTATAAACTTGTCACG GCCGCCAGAGGACATAAACTTACAACCAAATTTTTTATAAACTTGTCACG CCCGCCAGAGGACATAAACTTCCAACCAAATTTTTTATACACTTGTCACG CCCGCCAGAGGACATACACTCACAACCATATTTTTTATAAACTTGTCACG GCCGCCAGAGGTC-TAAACTTACAACCA-ATTTTTTATCAACTTGTCACA GCCGCCAGAGGTC-TAAACTTACAACCA-ATTTTTTATCAACTTGTCACA $\star \star$

CCAGATT-ATTACT - TAATAGTC-AAAACTTTCAACAACGGATCTCTTGG CCAGATT-ATTACT--AATAGTC-AAAACTTTCAACAACGGATCTCTTGG CTTGATTTATTATTACAATAGTC-AAAACTTTCAACAACGGATCTCTTGG AGAAATCTACGAXA - AACAXACAAAACTTACTAACAACGGATCTCTTGG - -AGATT-ATT-TT-TAATAGTC-AAAACTTTCAACAACGGATCTCTTGG - -AGATT-ATT-TT-TAATAGTC-AAAACTTTCAAXAACGGATCTCTTGG - -AGATT-ATT-TT-TAATAGAC-AAAACTTTCAACAACGGATCTCTXGG - -AGACT-ATT-TT-TAATAGTCCAAAACTTTCAACAACGGATCTCTTGG CCAGATT-ATTACT - -AATAGTC-AAAACTTCCAACAACGGATCTCTTGG CCAGATT-ATTACT-TAATAGTC-AAAACTTTCAACAACGGATCTCTTGG

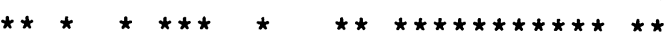

TTCTCGCATCGATGAAGAACGCAGC TTCTCGCATCGATGAAGAACGCAGC TTCTCGCATCGATGAAGAACGCAGC TTCTCGCATCGATGAAGAACGCAGC TTCTCGCATCGATGAAGAACGCAGC TXCTCGCATCGATGAAGAACGCAGC TXCTCGCATCGATGAAGAACGCAGC GTCTCGCATCGATGAAGAACGCAGC TTCTCGCATCGATGAAGAACGCAGC TXCTCGCATCGATGAAGAACGCAGC

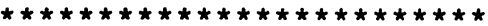

$\dagger=$ EMBL accession number; *indicates identical bases.

Figure 3 CLUSTAL V multiple sequence alignment of ITS1 and ITS2 PCR products amplified from pure cultures of Candida and archival tissue. 
Table 4 DNA distance values for ITS1 and ITS2 primer generated PCR products amplified from pure cultures of Candida and archival tissue

\begin{tabular}{|c|c|c|c|c|c|c|c|c|c|c|}
\hline & $\begin{array}{l}\mathrm{C} \text { albicans } \\
E M B L X 71088\end{array}$ & $\mathrm{C}$ albicans 655 & C tropicalis 340 & C krusei 3165 & $D 88.169$ & D91.98 & $D 92.865$ & $D 92.1639$ & D93.1497 & $D 95.227$ \\
\hline \multicolumn{11}{|l|}{$C$ albicans } \\
\hline$C$ albicans 655 & 0.0140 & 0.0000 & & & & & & & & \\
\hline$C$ tropicalis 340 & $0 \cdot 1078$ & $0 \cdot 1206$ & 0.0000 & & & & & & & \\
\hline C krusei 3165 & $0 \cdot 3856$ & 0.4103 & $0 \cdot 3625$ & 0.0000 & & & & & & \\
\hline D88.169 & 0.0436 & 0.0594 & $0 \cdot 1216$ & $0 \cdot 3324$ & 0.0000 & & & & & \\
\hline D91.98 & 0.0497 & 0.0660 & $0 \cdot 1305$ & $0 \cdot 3441$ & 0.0047 & 0.0000 & & & & \\
\hline D92.865 & 0.0650 & 0.0819 & $0 \cdot 1354$ & 0.3356 & 0.0190 & 0.0243 & $0 \cdot 0000$ & & & \\
\hline D92.1639 & 0.0693 & 0.0861 & 0.1524 & 0.3612 & 0.0284 & 0.0340 & 0.0387 & 0.0000 & & \\
\hline D93.1497 & 0.0046 & 0.0188 & $0 \cdot 1089$ & 0.3794 & 0.0488 & 0.0550 & 0.0706 & 0.0748 & 0.0000 & \\
\hline D 95.227 & 0.0000 & 0.0141 & $0 \cdot 1089$ & $0 \cdot 3914$ & 0.0438 & 0.0497 & 0.0650 & 0.0697 & 0.0046 & 0.0000 \\
\hline
\end{tabular}

base pairs) generated from the test tissue samples revealed greatest homology with the product obtained from $C$ albicans, and also concurred with previously reported sequences (EMBL accession no. X71088) for the targeted region of $C$ albicans rDNA (fig 3, table 4 ). The sequence of the larger ( 478 base pairs) PCR product obtained from tissue D92.791 had greatest homology with sequences obtained from the pure culture of $C$ glabrata.

\section{Discussion}

The presence of bacteria, protozoa and viruses in formalin fixed, paraffin wax embedded material has been demonstrated by PCR. ${ }^{9-11} 1920$ However, the detection of fungi in such material using gene amplification techniques has not been reported. The results of the present study have demonstrated that it is possible to detect and identify Candida species present in formalin fixed, paraffin wax embedded tissue by analysis of the primary structure of PCR amplified rDNA.

$C$ albicans was detected in 12 of the 18 specimens examined. $C$ glabrata was also present in two of these 12 samples. PCR products were not obtained with any of the four primer pairs used in three samples, whilst candidal DNA was not amplified in six. There are several possible explanations for the failure to produce a PCR product. Previous studies using PCR on formalin fixed, paraffin wax embedded tissues have noted the presence of endogenous inhibitors originating from the tissue. ${ }^{21}$ Furthermore, the size of extracted DNA may be relevant as degradation of target DNA during fixation in formalin has been documented. ${ }^{22}$ In this study three different fungal specific primer pairs were assessed in separate PCR protocols. Amplification was less successful as the length of target increased. This observation could be related to the decreased efficiency of the PCR on larger targets in formalin fixed material; the intermittent failure of PCR to amplify target DNA greater than 300 base pairs has been reported. ${ }^{21}$ The relatively high number of Candida within the agarose control preparation compared with the levels detected in the tissue samples may have partially compensated for this problem and permitted amplification of 535 base pair targets in this material.

Although PCR products were generated by both the Pcon $1 /$ Pcon 2 and ITS1/ITS 2 primer pairs, only the latter products were found to be suitable for the identification of Candida species. These primers amplified targets in 12 of the 18 specimens tested and sequencing of these products enabled the identification of both $C$ albicans and $C$ glabrata. Products identified as originating from $C$ glabrata were obtained from two samples, along with products characteristic of $C$ albicans. This finding may indicate infection involving two species of Candida.

The ability to identify Candida within human tissue provides an opportunity to increase our knowledge of the role of candidal species in disease. This is particularly important for patients with $\mathrm{CHC}$ because of the association between this form of candidiasis and the development of oral cancer.

In conclusion, this study has demonstrated that Candida species can be detected and identified in formalin fixed, paraffin wax embedded tissues by sequencing PCR amplified candidal rDNA sequences.

We should like to thank Mrs K Allsopp and Mrs J Hoy for their assistance in histopathology and DNA sequencing, respectively. D W Williams was supported by the Medical Research Council, UK.

1 Epstein JB, Komiyama K, Duncan D. Oral topical steroids and secondary oral candidiasis. FOral Med 1986;41:223-7. and secondary oral candidiasis. 7 Oral Med 1986;41:223-7.
Odds FC. Superficial candidoses - general aspects. In: Odds FC. Superficial candidoses - general aspects. In:
Candida and candidosis. London: Baillière Tindall, 1988: Candida

3 Heimdahl A, Nord CK. Oral yeast infection in immunocompromised and seriously diseased patients. Acta Odontol Scand 1990;48:77-84.

4 Odds FC. Pathogenesis of candidosis. In: Candida and candidosis. London: Baillière Tindall, 1988:252-78.

5 Bánóczy J. Follow-up studies in oral leukoplakia. $\mathcal{f}$ Maxillofac Surg 1977;5:69-75.

6 Walker DM, Arendorf T. Candidal leucoplakia, chronic multifocal candidosis and median rhomboid glossitis. In: multifocal candidosis and median rhomboid glossitis. In: Samaranayake LP, MacFarlane

7 Laiki RK, Scharf S, Faloona F, Mullis KB, Horn GT, Erlich $\mathrm{HA}$, et al. Enzymatic amplification of beta-globin genomic sequences and restriction site analysis for diagnosis of sickle cell anemia. Science 1985;230:1350-4.

8 Dubeau L, Weinberg K, Jones PA, Nichols PW. Studies on immunoglobulin gene rearrangement in formalin-fixed, inf 1988;130:588-94.

9 Chen M-L, Shieh YSC, Shim K-S, Gerber MA. Comparative studies on the detection of hepatitis B virus in parative studies on the detection of hepatitis B virus in frozen and paraffin embedded sections by the
chain reaction. Mod Pathol 1991;4:555-8.

10 Perosio PM, Frank TS. Detection and species identification of mycobacteria in paraffin-embedded sections of lung biopsy specimens by the polymerase chain reaction. $\mathrm{Am}$ F Clin Pathol 1993;100:643-7.

11 Ghossein RA, Ross DG, Salomon RN, Rabson AR. A search for mycobacterial DNA in sarcoidosis using the polymerase chain reaction. Am $\mathcal{f}$ Clin Pathol 1994;101: 733-7

12 Magee BB, D'Souza TM, Magee PT. Strain and species identification by restriction fragment length polymorphisms in the ribosomal DNA repeat of Candida species. F Bacteriol 1987;169:1639-43.

13 Neisters HGM, Goessens WHF, Meis JFMG, Quint WGV. Rapid polymerase chain reaction-based assays for Candida species. F Clin Microbiol 1993;31:904-10. 
14 Williams DW, Wilson MJ, Lewis MAO, Potts AJC. Identification of Candida species by PCR and restriction fragment length polymorphism analysis of intergenic spacer regions of ribosomal DNA. F Clin Microbiol 1995;33: 2476-9.

15 White TJ, Bruns T, Lee S, Taylor J. Amplification and direct sequencing of fungal ribosomal RNA genes for phylogenetics. In: Innis MA, Gelfand DH, Sninsky JJ, White TJ, eds. PCR protocols: A guide to methods and applications. London: Academic Press, 1990:315-22.

16 Holmes AR, Cannon RD, Shepherd MG, Jenkinson HF. Detection of Candida albicans and other yeasts in blood Detection of Candida albicans and other
by PCR. $f$ Clin Microbiol 1994;32:228-31.

17 Sambrook J, Fritsch EF. Molecular cloning: a laboratory manual. New York: Cold Spring Harbour Laboratory Press, 1989.
18 Devereux J, Haeberli P, Smithies O. A comprehensive set of sequence analysis programmes for VAX. Nucleic Acids

Res 1984;12:387-95.
19 Tsai MM, O'Leary TJ. Identification of Toxoplasma gondii in formalin-fixed, paraffin-embedded tissue by polymerase chain reaction. Mod Pathol 1993;6:185-8.

20 Chebab FF, Xiao X, Kan YW, Yen TSB. Detection of cytomegalovirus infection in paraffin embedded tissue specimens with the polymerase chain reaction. Mod Pathol 1989;2:75-8.

21 An SF, Fleming KA. Removal of inhibitor(s) of the polymerase chain reaction from formalin fixed, paraffin wax embedded tissues. 7 Clin Pathol 1991;44:924-7.

22 Mies C. Molecular pathology of paraffin-embedded tissue. Current clinical applications. Diagnostic Molecular Patho$\log y$ 1992;1:206-11. 